\title{
Impact of measurable physical phenomena on contact thermal comfort
}

\author{
Miloš Fojtlín ${ }^{1, *}$, Jan Pokorný ${ }^{1}$, Jan Fišer $^{1}$, Róbert Toma $^{1}$, and Ján Tuhovčák ${ }^{1}$ \\ ${ }^{1}$ Department of Thermodynamics and Environmental Engineering, Energy Institute, Faculty of mechanical engineering, Brno University \\ of Technology, The Czech Republic.
}

\begin{abstract}
Cabin HVAC (Heating Ventilation and Air-conditioning) systems have become an essential part of personal vehicles as demands for comfortable transport are still rising. In fact, $85 \%$ of the car trips in Europe are shorter than $18 \mathrm{~km}$ and last only up to 30 minutes. Under such conditions, the HVAC unit cannot often ensure desired cabin environment and passengers are prone to experience thermal stress. For this reason, additional comfort systems, such as heated or ventilated seats, are available on the market. However, there is no straightforward method to evaluate thermal comfort at the contact surfaces nowadays. The aim of this work is to summarise information about heated and ventilated seats. These technologies use electrical heating and fan driven air to contact area in order to achieve enhanced comfort. It is also expected, that such measures may contribute to lower energy consumption. Yet, in real conditions it is almost impossible to measure the airflow through the ventilated seat directly. Therefore, there is a need for an approach that would correlate measurable physical phenomena with thermal comfort. For this reason, a method that exploits a measurement of temperatures and humidity at the contact area is proposed. Preliminary results that correlate comfort with measurable physical phenomena are demonstrated.
\end{abstract}

\section{Introduction}

Development of personal transport is greatly influenced by efforts to reduce energy consumption, emissions and increase safety on roads. However, these demands are contradictory when thinking in conventional technologies. Therefore, new concepts of efficient energy utilisation are investigated. One of the indispensable systems that contribute to enhanced comfort in a cabin, as well as to considerable energy consumption, is the system of HVAC (Heating Ventilation and Air-conditioning). HVAC systems drain at least $7 \%$ of total energy consumption of a vehicle, whereas, in peak loads this could be quadruped $[1,2]$. Particularly a driving range of hybrid or electric vehicles is sensitive to climate, as it is demonstrated in the work of Kambly and Bradley [1]. The more energy needed to manage cabin microclimate, the lower the driving range. A current concept of the HVAC systems continually treats the incoming air and distribute it according to passengers' demands into the cabin. On the other hand, there are more energy efficient ways to satisfy passengers' needs, such as contact heating or cooling. In fact, such technologies are routinely installed into modern vehicles. Most common are heated or ventilated seats, a heated steering wheel and armrests. However, the greatest potential to enhance cabin comfort has the seat, as it creates a considerable contact area with a passenger's body. To these days, complex knowledge to assess contribution of seats to thermal comfort is missing.

Available standards, ISO 14505:2006, ISO 7730, and thermo-physiological models, such as Fiala model, are considered to be the most widely accepted approaches to evaluate thermal comfort in car cabins [3]. Yet, the first two methodologies are not ultimately applicable to contact parts and the Fiala model requires detailed inputs that are not easily accessible in field conditions. Cengiz and Babalik $[4,5]$ carried out an on-the-road experiment with the aim of examining impact of seat cover materials on the thermal comfort. Even thought, they did not investigate heated or ventilated seats, the properties of cover materials influence heat and moisture transport from a human body. The results of their studies clearly shows two important findings: (a) there are significantly different thermal sensations perceived on the back and the seat; (b) even when the overall perceived thermal sensation was between neutral to slightly warm, contact comfort on the back and the seat was compromised due to skin wettedness. This is, however, expectable, as the seat acts like an additional thermal insulation and a barrier to water vapour. As a result, heat and moisture accumulates in the clothing, what contributes to discomfort [6]. Thermal and moisture equilibrium is, therefore, needed. This is also the first condition to achieve thermal comfort [7].

A human body generates heat of around $60 \mathrm{~W} . \mathrm{m}^{-2}$ in a calm sitting posture. Similarly, insensible perspiration occurs at all times because of water vapour diffusion.

* Corresponding author: milos.fojtlin@vutbr.cz

(C) The Authors, published by EDP Sciences. This is an open access article distributed under the terms of the Creative Commons Attribution License 4.0 (http://creativecommons.org/licenses/by/4.0/). 
Under thermal neutral conditions a person perspires at least $30 \mathrm{~g}$ of water vapour per hour [8]. Heavier rate of sweating occurs in situations, when a body cooling is insufficient. Therefore, seat ventilation is meaningful if excessive heat and moisture need to be led away from the contact area. Generally, two types of seat ventilation systems are used: (a) push systems, blowing the air into the contact area; (b) pull systems, extracting the air from the contact area. However, differences in efficiency have not been found in the literature.

In the Nilsson's thesis [7], effects of ventilated seats on seat thermal insulation properties were tested. It was found that the additional thermal insulation of a ventilated seat running at the highest power level is negligible. However, quantification of efficiency of ventilation is in this case problematic. The air flows through the seat cover material and layers of clothing. Further, the effective ventilation area depends on occupant's body proportions. Additional tests with added moisture (a piece of wet cloth placed on the seat) showed that ventilated seat helps reducing humidity at the contact area, but with undesirably cold sensation for the seat occupant.

Another system of enhancing comfort on the seat is a system of surface heating. A heated seat should ensure quick heat up in cold conditions to desired surface temperature. Oi et al. [9] recommend temperatures on the heated seat of around $34{ }^{\circ} \mathrm{C}$ depending on the ambient conditions. On the other hand, long exposures to temperatures above $43{ }^{\circ} \mathrm{C}$ may cause skin burns.

Distribution of heat on the surface of the seat is accomplished by resistance wires, which are embedded under the seat cover. Typical temperature fields on the surface of the heated seat are depicted in the Fig. 1. On the left side, the heating is on without an occupant, and a temperature field of the same heated seat after $30 \mathrm{~min}$ of occupation by a passenger is on the right hand side.

Next, findings in literature suggest that not only optimal temperature on the seat is necessary, but also moisture management is crucial to achieve thermal comfort. For example, Cengiz and Babalik [4] used skin wttedness sensor attached to the skin to measure the amount of moisture on the back. Skin wittedness $w(-)$ is defined as follows:

$$
w=\frac{p_{s k}-p_{a}}{p_{s s k}-p_{a}}
$$

where $p_{s k}$ is water vapour pressure at skin; $p_{s s k}$ is saturated vapour pressure at skin; $p_{a}$ is ambient vapour pressure; all units are in $P a$. Capability to relate thermal comfort with skin wittedness is limited, because of its relativity to temperature. Moreover, the results from the study of Cengiz and Babalik [4] are presented as average values. Therefore, it is not possible to identify skin wettedness in time and its correlation with comfort.

Pasut [10] demonstrated an enhancement of comfort on heated and ventilated office chairs. In addition, power saving potential was stated. However, the participants involved in the experiment were asked to adjust heating, ventilation and clothing to match their needs. On the other hand, automatic or semi-automatic control of the seat heating and ventilation should be available in the cabins to avoid distraction of the driver.

Based on the literature findings, heated and ventilated seats can clearly enhance human thermal comfort. However, the intensity of heating or ventilation must be applied with respect to possible health risks. The aim of the experimental work of this paper is to gather pilot data about comfort and thermal sensation on a heated seat. Two major contact parts will be examined: the seat and the back surface temperatures. Subjective votes will be obtained from a pool of participants.

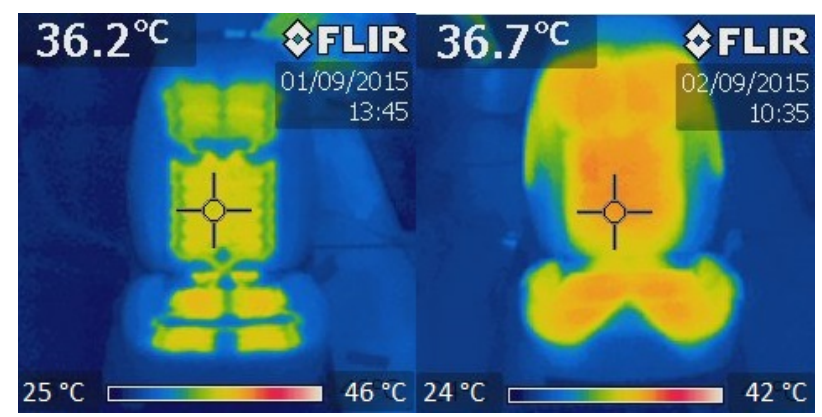

Fig. 1 Temperature fields on heated seats. Left: heating on; Right: heating on after $30 \mathrm{~min}$ of occupation.

\section{Methods}

The experiment was designed to verify correlation of a subjective perception with objective (measurable) phenomena at the contact surfaces. To do so, objective parameters - temperatures, were measured directly on the surface of a textile covered heated seat. Distribution of the temperature sensors is depicted in the Fig. 2. Accuracy of temperature measurements was $\pm 0.4{ }^{\circ} \mathrm{C}$, such precision should be sufficient for the given purpose.

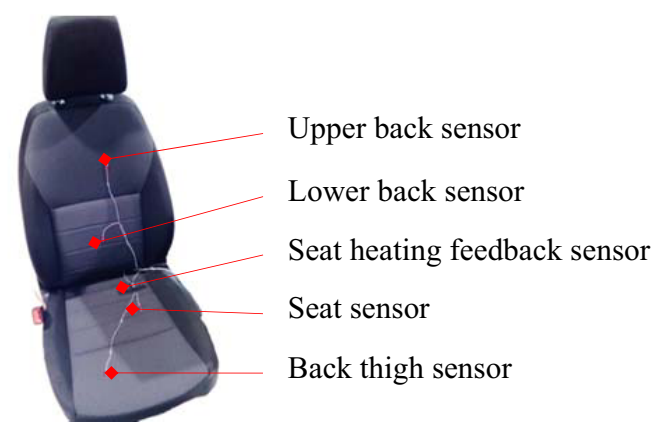

Fig. 2 Distribution of temperature and humidity sensors on the seat.

Next, the subjective data, thermal comfort and thermal sensation, were harvested from a pool of volunteers. The participants involved in the study were 14 males, and 6 females, all of them active drivers. Age of the subjects covered a span of 20 to 60 years old. Average body mass index (BMI) was 25 for men and 23 for women. Clothing of participants consisted of, underwear, socks, shoes, trousers, a cotton T-shirt and a light pullover or a cotton shirt. This was found to be the standard light winter clothing in Central Europe suitable for driving. Before the actual measurements, it was important to ensure similar metabolic rate of the 
volunteers at the beginning of the tests. Otherwise, there might be numerous unknown personal factors involved in the results of the study. Therefore, no beverages, food or smoking was allowed two hours before the measurements (lukewarm water only). It was also requested to come to the session rested; no minor or major sickness was acceptable.

Further, the experimental procedure consisted of preconditioning phase and measurement phase. Both activities took place at Brno University of Technology, in a laboratory equipped with a climate chamber.

The preconditioning was mandatory for all participants, who were asked to stay in a defined environment $\left(23{ }^{\circ} \mathrm{C}, \mathrm{Rh} 50 \%\right)$ at least one hour in a calm sitting position. After this, a group of four volunteers was seated on the seats, which were arranged in the vertices of the $3 \times 3 \mathrm{~m}$ square in the climate chamber. Preconditioning of the chamber took at least 90 minutes to reach uniform ambient temperature of $16{ }^{\circ} \mathrm{C}$ $\pm 1{ }^{\circ} \mathrm{C}$. Relative humidity was set to $50 \%$ and the airspeed in the chamber was less than $0.1 \mathrm{~m} . \mathrm{s}^{-1}$.

Volunteers took seats according to a random seating plan to avoid systematic errors. The seat heating was switched on right after the participants were seated. The seat heating was regulated by a feedback sensor attached to the seat cushion (Fig. 2). The prescribed seat surface temperature was $38^{\circ} \mathrm{C}$ and the participants were not able to change this temperature pre-set. In case of emergency, they were allowed to switch off the heating themselves. The same temperature pre-set on back and seat cushion was used.

One measurement sitting lasted 30 minutes. The first subjective evaluation took place right before entering the chamber (time $-3 \mathrm{~min}$ ). The following evaluation continued right after sitting on the seat (time 0 ). Then the seat heating was switched on. Next, the evaluation continued in 6 minutes intervals. One extra 3 minute interval was added to allow detailed evaluation of the seat heat up period.

The according subjective scales are shown in the Table 1; please note that comfort scale has not a zero value to distinguish between comfortable and uncomfortable states.

Table 1. Scales of thermal sensation and comfort.

\begin{tabular}{|c|c|c|c|}
\hline \multicolumn{2}{|c|}{ Thermal sensation } & \multicolumn{2}{c|}{ Thermal comfort } \\
\hline+3 & Hot & +3 & Very comfortable \\
\hline+2 & Warm & +2 & Comfortable \\
\hline+1 & Slightly warm & +1 & Just comfortable \\
\hline 0 & Neutral & - & \\
\hline-1 & Slightly cool & -1 & Just uncomfortable \\
\hline-2 & Cool & -2 & Uncomfortable \\
\hline-3 & Cold & -3 & Very uncomfortable \\
\hline
\end{tabular}

\section{Results and discussion}

Results are presented separately for back and seat cushion. Average values from twenty subjective votes are presented together with the standard deviation values (SD) in Fig. 3 and 4.

Time course, in the graphs, begins with value $-3 \mathrm{~min}$, which represents value when the test subjects were in the preconditioning room just before entering the climate chamber. At this point, most of the participants were feeling comfortable, average thermal comfort vote was around 1.5. The preconditioning phase was successful. The reported thermal sensation was between neutral and slightly warm. At this point, the seat and the back surface temperatures were matching with the ambient temperature inside the chamber, $16{ }^{\circ} \mathrm{C}$.

In the next time step, time 0 - right after the seating in the chamber, the participants reported drop in thermal the comfort and the sensation. The back part was evaluated as slightly colder because of its greater sensitivity to the cold stimulus. Average value of thermal comfort fell below 1. However, the SD of the comfort votes was approximately \pm 1.5 at both body parts. This means that there was large diversity in the comfort perception, from very uncomfortable to comfortable. Such findings were stated also in other papers $[4,9,10]$.

Between the third and the sixth minute, the seat surface temperature reached its stable average value of around $41.2{ }^{\circ} \mathrm{C}$ on the back part and $39.9{ }^{\circ} \mathrm{C}$ on the seat cushion. Fluctuations in the surface temperatures, expressed by SD, were observed and were typically less than $2{ }^{\circ} \mathrm{C}$. As a cause of this, variability in a body constitution and a seating style was identified.

During the seat heat up period, the comfort votes reached the highest rating. However, the further development of the votes on the seat cushion shows gradual decrease of comfort, whereas, the thermal sensation remains constant between slightly warm and warm. Moreover, the comfort votes were becoming less uniform towards the end of the experiment.

Slightly different situation was found on the seat. The mean value of the thermal sensation was lower than that of the back, but still within the borders of slightly warm and warm. Thermal comfort votes were also gradually decreasing, however, at the end of the experiment, the mean value was still above 1 , just comfortable. Possible answer to these discrepancies between the seat and the back might be a pressure distribution on the seat that influences heat transfer to the body. The greater the pressure on the seat cushion, the better the contact with the seat heating. Opposite situation is on the back, where the contact pressure is lower. However, even the participants were instructed to sit straight on the seats, they tended to bend their backs. This also causes imperfect contact with the seat surface, what was also reflected by higher average temperature on the back.

Next, it was important to find an optimal placement of the feedback sensor. Even the surface temperature was set to $38{ }^{\circ} \mathrm{C}$, the temperature peaks reached more than $44{ }^{\circ} \mathrm{C}$ in some cases. Variability in the seat surface temperature might be avoided, in the future, if at least two feedback sensors were used, one for the back and 
one for the seat cushion. However, this test simulated real conditions with one sensor only.

Comfortable skin temperature on the heated seat is approximately $34{ }^{\circ} \mathrm{C}$ [9]. In this experiment, the comfort was scarified by higher skin temperatures to reveal a comfort vote development under warmer conditions. Preliminary results show that there is a good correlation between the contact temperature and thermal sensation. On the other hand, thermal comfort cannot be correlated only with temperature. Some additional parameter is needed, such as skin wittedness or other non-temperature related index. To prove this, further tests are needed.

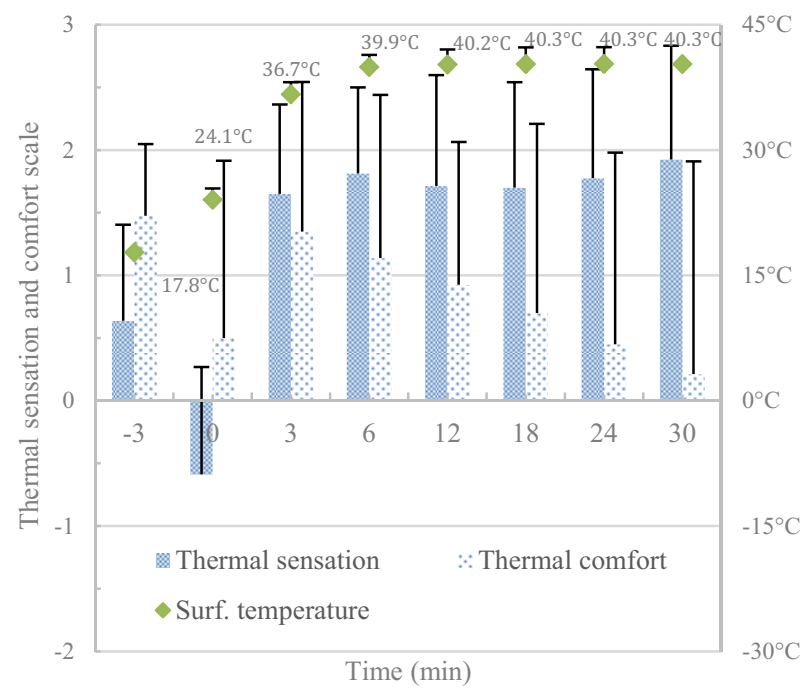

Fig. 3 Ambient $16^{\circ} \mathrm{C}$ - Seat - thermal sensation, thermal comfort, and surface temperature; average values with standard deviation.

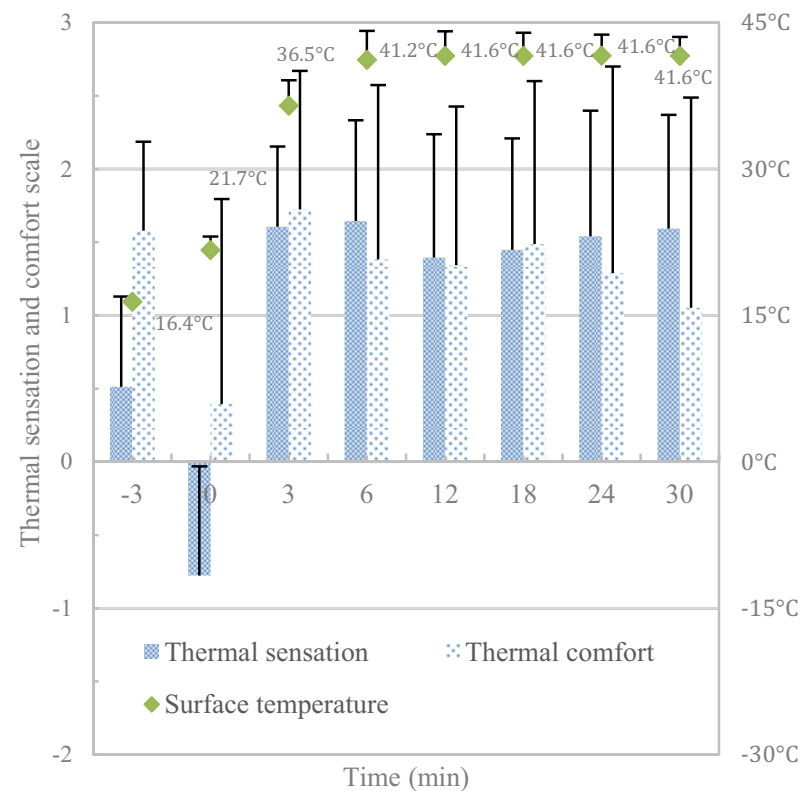

Fig. 4 Ambient $16^{\circ} \mathrm{C}$ - Back - thermal sensation , thermal comfort, and temperature; average values with standard deviation.

\section{Conclusion}

Heated and ventilated seats were proved to be useful in enhancing thermal experience. The findings from the experiment and the literature suggest that there is a good correlation between the surface temperatures and thermal sensation. Yet, thermal sensitivity of the back differs from that of the seat. Further, the standard deviation of the thermal comfort votes was gradually rising throughout the experiment. This means that there is a rising diversity in the perception of thermal comfort. The reason for this should be explained in further studies with additional objective parameters, such as skin wettedness.

Next, one temperature feedback sensor was found to be insufficient to control the seat surface temperature effectively. The surface temperature was set to $38{ }^{\circ} \mathrm{C}$, whereas, the resulting contact temperatures at the end of the experiment were: $40.3{ }^{\circ} \mathrm{C} \pm 1.3{ }^{\circ} \mathrm{C}$ on the seat cushion, $41.6{ }^{\circ} \mathrm{C} \pm 2.3{ }^{\circ} \mathrm{C}$ on the back rest.

\section{Acknowledgement}

The research was support from the project RP-906-2300713/1120, Brno University of Technology, The Czech Republic.

\section{References}

1. K. R. Kambly, T. H. Bradley, J. Power Sources 259, 117-124 (2014)

2. C. De Cauwer, J. Van Mierlo, T. Coosemans, Energies 8,8573-8593 ( 2015)

3. C. Croitoru, I. Nastase, F. Bode, A. Meslem, A. Dogeanu, Renew. Sustain. Energy Rev. 44, 304-318 (2015)

4. T. G. Cengiz, F. C. Babalik, Appl. Ergon. 38, $337-$ 347 (2007)

5. T. G. Cengiz, F. C. Babalik, Int. J. Ind. Ergon. 39, 287-294 (2009)

6. J. Toftum, A. S. Jørgensen, P. O. Fanger, Energy Build. 28, 1-13 (1998)

7. H. O. Nilsson, Comfort climate evaluation with thermal manikin methods and computer simulation models (Thesis, University of Gavle, 2004)

8. V. T. Bartels, Appl. Ergon. 34, 393-399 (2003)

9. H. Oi, K. Tabata, Y. Naka, A. Takeda, Y. Tochihara, Appl. Ergon. 43, 360-367 (2012)

10. W. Pasut, H. Zhang, E. Arens, Y. Zhai, Build. Environ. 84, 10-21 (2015) 